\title{
PRESENTATION AND OUTCOMES OF AORTOFEMORAL BYPASS SURGERY IN PATIENTS WITH AORTOILIAC OCCLUSIVE DISEASE. FOUR YEARS' EXPERIENCE AT A TERTIARY CARE HOSPITAL
}

\author{
Muhammad Khalid Siddique, Waqas Ahmed*, Khalid Pervaiz Butt, Khalid Ibrahim Akhtar, Hamna Khalid**, \\ Muhammad Tariq Khan $* * *$ \\ Combined Military Hospital Malir/National University of Medical Sciences (NUMS) Pakistan, *Combined Military Hospital Quetta/ National \\ University of Medical Sciences (NUMS) Pakistan, **Pak Emirates Combined Military Hospital / National University of Medical Sciences \\ (NUMS) Rawalpindi Pakistan, ${ }^{* * *}$ Combined Military Hospital Lahore/National University of Medical Sciences (NUMS) Pakistan
}

\section{ABSTRACT}

Objective: To highlight the presentation and outcomes of Aortofemoral bypass surgery at a tertiary care hospital. Study Design: Prospective observational study.

Place and Duration of Study: Vascular Surgery department, Combined Military Hospital Lahore, from Jan 2015 to Dec 2019.

Methodology: A total of 23 patients between 50-80 years of age presenting with critical limb ischemia due to Aortoiliac occlusive arterial disease type C or D of Trans-Atlantic inter Society Consensus (TASC) II classification confirmed on CT Angiogram, were included in the study. The clinical presentation, co-morbid illnesses, history of smoking, obesity, post operative patency of graft, wound infection, amputation rates, and mortality were documented on a structured proforma. All patients were followed up at 1, 6, 12 and 24 months of surgery. Outcomes were assessed in terms of graft patency, wound infection, limb survival, amputations and mortality. Data was analyzed by SPSS version 23.0.

Results: The mean age of patients was $71.04 \pm 7.29$ years. Most patients presented with rest pain $(56.5 \%)$. The frequency of smokers was $78.3 \%$ while $34.8 \%$ patients had both diabetes mellitus and ischemic heart disease. Hyperlipidemia was present in $30.4 \%$ patients. Two patients $(8.7 \%)$ developed superficial surgical site infection. The limb salvage rate was $95.7 \%$ and the mortality rate was $4.3 \%$.

Conclusion: Aortofemoral bypass surgery is a safe and highly effective treatment modality for the management of aortoiliac occlusive arterial disease in experienced hands. Limb salvage can be successfully achieved in more than $95 \%$ cases.

Keywords: Amputation, Aortofemoral bypass, Aortoiliac occlusive disease, Critical limb ischemia, Gangrene.

This is an Open Access article distributed under the terms of the Creative Commons Attribution License (http://creativecommons.org/licenses/by/4.0), which permits unrestricted use, distribution, and reproduction in any medium, provided the original work is properly cited.

\section{INTRODUCTION}

Atherosclerotic disease of abdominal aorta and iliac arteries is one of the most common therapeutic challenges encountered by vascular surgeons. It is manifested as symptomatic arterial insufficiency of the lower extremities, producing symptoms from mild claudication to more severe Critical Limb Ischaemia (CLI) ${ }^{1}$. The patients presenting with claudication secondary to aortoiliac disease are nearly a decade younger than those with claudication due to infrainguinal occlusive disease, despite the similar etiology and risk factors $^{2}$. Depending upon the severity of the disease,

Correspondence: Dr Muhammad Khalid Siddique, HOD Surgery, Combined Military Hospital Malir Pakistan

Received: 08 Jun 2020; revised received: 08 Jul 2020; accepted: 13 Jul 2020 various management strategies are used ranging from conservative to radical open bypass surgery. Supervised Exercise and Best Medical therapy are the cornerstones of the conservative management $^{3}$. In case of failure of conservative treatment patient is to be managed invasively either with open surgery or through endovascular procedures.

Portuguese surgeon Dos Santos did first successful endarterectomy of common femoral artery in $1947^{4}$. Four years later in 1951, Wylie et al in San Francisco extended this technique to Aortoiliac level, but it took further 10 years to start Aortic Bypass after the advent of synthetic grafts $^{5}$. Since then the advancements in the graft material and surgical techniques have 
significantly improved the results and outcome of Aortofemoral bypass surgery in correctly identified cohort. The Trans Atlantic Inter-Society Consensus (TASC) classification currently provides an anatomic guide for the therapy in invasive group. In general, TASC type A lesions are best treated with endovascular therapy, whereas TASC type D lesions are best treated with surgical revascularization 6 .

The rationale of conducting this study was that there is dearth of research protocols on the Aortofemoral bypass graft surgery in the Pakistani literature. The findings of this study will help in gathering data for establishment of evidence based practices regarding management of Aortofemoral bypass surgery in patients presenting with Aortoiliac occlusive arterial disease in Pakistani local population.

\section{METHODOLOGY}

This prospective observational study was carried out at the Department of Vascular Surgery, Combined Military Hospital, Lahore after ethics review committee approval vide IRB certificate number $203 / 20$. The duration of study was 4 years, from January 2015 to December 2019. The sample size was calculated by the WHO sample size calculator as follows: confidence level $=95 \%$; absolute precision required $=0.07$ and anticipated population proportion of graft patency $=97 \%$. The sample size came out to be 23 patients. The sampling method used was non-probability consecutive sampling. A written consent was taken from all patients included in the study.

The sample inclusion criteria included patients of both genders presenting with critical limb ischemia due to aortoiliac occlusive arterial disease type C or D of Trans-Atlantic inter Society Consensus (TASC) II classification confirmed on CT angiogram of abdominal aorta. Patients were diagnosed as CLI by history of chronic ischemic rest pain in one or both lower limbs along with ulcers or gangrene secondary to arterial occlusive disease. The cutoff value for ankle pressure was $<50 \mathrm{mmHg}$ in patients with ischemic rest pain and an ankle pressure of $<70 \mathrm{mmHg}$ in patients presenting with toe ulcers or gangrene ${ }^{8}$. The exclusion criteria set for the study was patients having severe sepsis, patients unfit for general anesthesia (GA) and patients with concomitant proximal aortic occlusion.

Demographic details of all patients included in the study including history of smoking, comorbids including diabetes mellitus (DM), hypertension (HTN), chronic kidney disease (CKD), ischemic heart disease (IHD) and hyperlipidemia were documented. The symptoms like buttock claudication, impotence, rest pain, tissue loss and diminished femoral pulses were also documented. The BMI of patients was also documented. All patients fulfilling the operational definition of CLI underwent computed tomography angiogram (CTA) with 3-D reconstruction to determine the level of occlusion from abdominal aorta till peripheral run off vessels. The workup of patients was completed and they were planned for aortofemoral bypass graft.

All risks, potential complications and benefits were explained in detail to the patient and their families before surgery. All the patients were operated under GA with intra-arterial pressure line monitoring, epidural catheter, foley catheter and pre-operative antibiotics. The femoral arteries were exposed through longitudinal incisions in each groin and control of CFA, SFA and PFA arteries on each side was achieved through vessel loops.

Infra renal aorta was exposed through midline longitudinal incision extending downwards from xiphoid process to below the umbilicus. Abdomen was explored for any other pathology. Ligament of Treitz was then taken down and duodenum was mobilized to the right to access the infra renal aorta. The exposure was facilitated with the help of application of Omni tract retractor system. Infra renal aorta was exposed till bifurcation. Retroperitoneal tunnels were completed on either side for the passage of femoral limbs of the graft anterior to iliac vessels but posterior to the ureters. Once the dissection work was complete 5000 unit IV Heparin was given. 
After applying proximal and distal aortic clamps, about $3 \mathrm{~cm}$ longitudinal aortotomy was fashioned over anterior aspect of infra renal aorta at as proximal disease free part as possible. Loose debris and mural thrombus was removed from the dissected part. Beveled top end of the graft was anastomosed in end to side fashion with proline 3/0 round body suture. After completion of abdominal portion of the procedure, the graft limbs were clamped with soft clamps and flushed

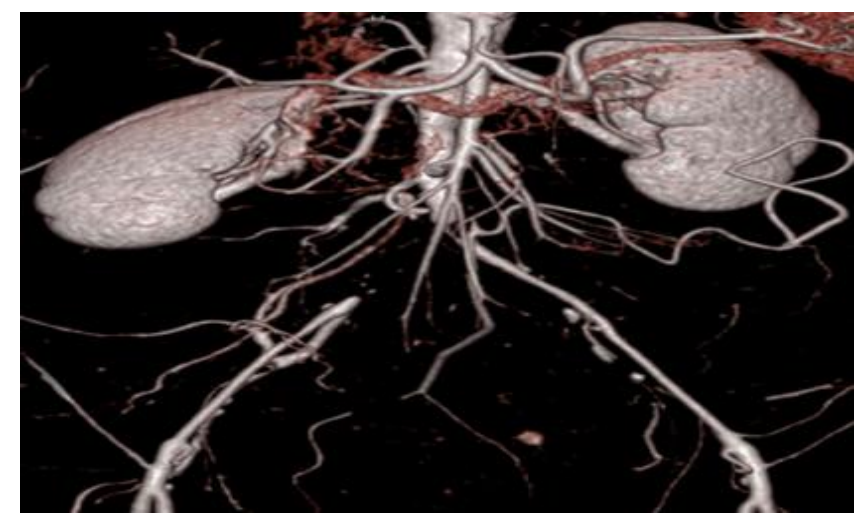

Figure-1: CT Angiogram of a 65 years old patient.

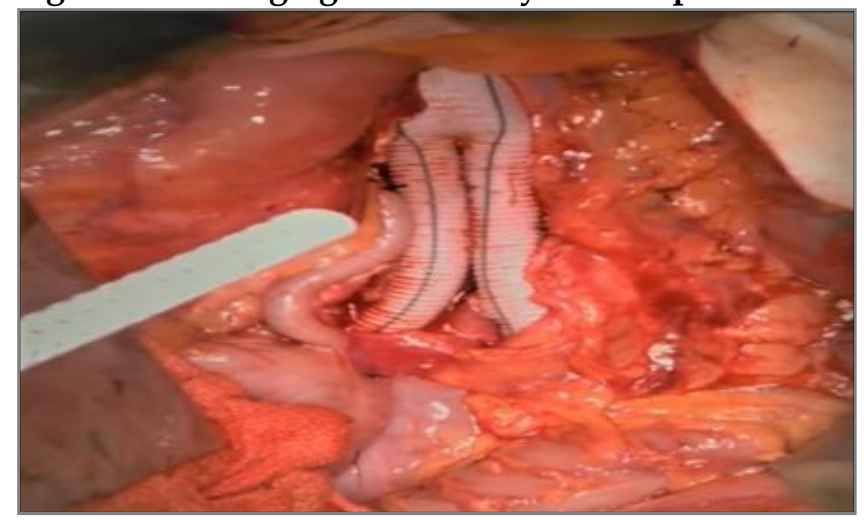

Figure-2: Aortobifemoral bypass graft in place in the same patient.

with Heparinized saline. They were then passed through the tunnels for distal anastomosis. Proximal femoral control was obtained with application of satinsky clamp placed from a lateral direction while distal control was achieved through Bulldog and profunda clamps. Longitudinal arteriotomy was done extending till the origin of profunda femoris artery. The distal anastomosis was done with proline $5 / 0$ using end to side technique.
Adequate distal perfusion and absence of distal embolization was ensured per operatively. Need of further procedure for distal revascularization if required was assessed at this point. After achieving hemostasis, retro peritoneum was closed over the graft. A sleeve of omentum was placed between graft and duodenum to prevent aorto-enteric fistula if required. Abdomen was

Table-I: Summary of demographics and presentation.

\begin{tabular}{l|c|c}
\hline \multirow{2}{*}{ Variable } & Groups & $\begin{array}{c}\text { No. of } \\
\text { Patients (\%) }\end{array}$ \\
\hline \multirow{2}{*}{ Age (years) } & $50-65$ & $6(26.1 \%)$ \\
\cline { 2 - 3 } Presentation & $66-80$ & $17(73.9 \%)$ \\
\cline { 2 - 3 } & Rest pain & $13(56.5 \%)$ \\
\cline { 2 - 3 } & Toe gangrene & $6(26.1 \%)$ \\
\cline { 2 - 3 } & Forefoot gangrene & $3(13.0 \%)$ \\
\hline \multirow{4}{*}{ Smoking } & Soot gangrene & $1(4.3 \%)$ \\
\cline { 2 - 3 } & Non-smokers & $18(78.3 \%)$ \\
\hline \multirow{4}{*}{ Co-morbids } & Diabetes mellitus & $17(21.7 \%)$ \\
\cline { 2 - 3 } & Hypertension & $16(69.6 \%)$ \\
\cline { 2 - 3 } & $\begin{array}{c}\text { Ischemic heart } \\
\text { disease }\end{array}$ & $12(52.2 \%)$ \\
\cline { 2 - 3 } & $\begin{array}{c}\text { Chronic kidney } \\
\text { disease }\end{array}$ & $2(8.7 \%)$ \\
\cline { 2 - 3 } & Hyperlipidemia & $7(30.4 \%)$ \\
\hline
\end{tabular}

Table-II: Outcomes of the study data stratification for age, gender, smoking, and co-morbids illnesses for Graft patency is given in table-III.

\begin{tabular}{l|c|c}
\hline $\begin{array}{l}\text { Outcome } \\
\text { Variable }\end{array}$ & Outcome & $\begin{array}{c}\text { No. of } \\
\text { Patients (\%) }\end{array}$ \\
\hline $\begin{array}{l}\text { Surgical site } \\
\text { infection }\end{array}$ & Yes & $2(8.7 \%)$ \\
\cline { 2 - 3 } & No & $21(91.3 \%)$ \\
\hline \multirow{3}{*}{ Amputation } & Toe & $6(26.1 \%)$ \\
\cline { 2 - 3 } & Forefoot & $3(13.0 \%)$ \\
\cline { 2 - 3 } & Below knee & $1(4.3 \%)$ \\
\hline \multirow{2}{*}{ Graft Patency } & Yes & $21(91.3 \%)$ \\
\cline { 2 - 3 } & No & $2(8.7 \%)$ \\
\hline \multirow{2}{*}{ Mortality } & Yes & $1(4.3 \%)$ \\
\cline { 2 - 3 } & No & $22(95.7 \%)$ \\
\hline
\end{tabular}

closed with proline 1 as mass closure. Groin wounds after through lavage were closed with absorbable Vicryl sutures in multi layers. Skin was closed with proline in interrupted fashion. Dacron graft was used in all cases. Postoperatively patients were followed up at 1, 6, 12 and 24 
month intervals. The patency of the graft was confirmed by hand held Doppler and ultrasound Doppler where required. Patients developing gangrene in the follow up period had amputations as required. The overall mortality rate was assessed at 2 year follow up.

All the data was collected on a pre-designed proforma. Follow up was ensured by taking contact numbers of patients. Data was entered in and analyzed by using SPSS version 23.0. Mean and standard deviation were calculated for age. Frequencies and percentages were computed for patients $(91.3 \%)$ were males and only 2 patients $(8.7 \%)$ were females. The most common presentation was patients with CLI having rest pain which was seen in 13 patients (56.5\%). One patient, an 80 years old male presented with gangrene of whole foot. Most of the patients were smokers $(78.3 \%)$. Five patients $(21.7 \%)$ had a body mass index (BMI) of more than $30 \mathrm{Kg} / \mathrm{m}^{2}$. Hyperlipidemia was found in 7 patients $(30.4 \%)$ while the DM and IHD combination was the most common co-morbid illness found in 8 patients (34.8\%).

Table-III: Graft patency in patients.

\begin{tabular}{|c|c|c|c|c|}
\hline \multicolumn{5}{|c|}{ Graft Patency } \\
\hline \multicolumn{2}{|r|}{ Variables } & \multicolumn{2}{|c|}{ Graft Patency } & \multirow{2}{*}{$p$-value } \\
\hline Variable & Groups & Yes & No & \\
\hline \multirow{2}{*}{ Age (years) } & $50-65$ & $5(21.7 \%)$ & $1(4.3 \%)$ & \multirow{2}{*}{0.420} \\
\hline & $66-80$ & $16(69.6 \%)$ & \multirow{2}{*}{$\begin{array}{l}1(4.3 \%) \\
1(4.3 \%)\end{array}$} & \\
\hline \multirow{2}{*}{ Gender } & Male & $20(87.0 \%)$ & & \multirow{2}{*}{0.030} \\
\hline & Female & $1(4.3 \%)$ & \multirow{2}{*}{$1(4.3 \%)$} & \\
\hline \multirow{2}{*}{ Smoking } & Smokers & $17(73.9 \%)$ & & \multirow{2}{*}{0.311} \\
\hline & Non-smokers & $4(17.4 \%)$ & $1(4.3 \%)$ & \\
\hline \multirow{5}{*}{ Comorbids } & Diabetes mellitus & $16(63.6 \%)$ & $1(4.3 \%)$ & 0.420 \\
\hline & Hypertension & $14(60.9 \%)$ & $2(8.7 \%)$ & 0.328 \\
\hline & Ischemic heart disease & $10(43.5 \%)$ & - & 0.156 \\
\hline & Chronic kidney disease & - & $2(8.7 \%)$ & $<0.001$ \\
\hline & Hyperlipidemia & $6(26.1 \%)$ & $1(4.3 \%)$ & 0.529 \\
\hline Table-IV: Out & es of aortofemoral bypas & lies. & & \\
\hline Study & Year & Patients & Mortality & 5 year Patency rate \\
\hline Sharma et al 15 & 2018 & 133 & $0.8 \%$ & $77.2 \%$ \\
\hline Tanaka et al16 & 2019 & 122 & $9 \%$ & $91.2 \%$ \\
\hline Chiu et al ${ }^{17}$ & 2010 & 5738 & $4.1 \%$ & $86.3 \%$ \\
\hline Igari et al 18 & 2020 & 21 & - & $94.8 \%$ \\
\hline Lee et $_{\text {al }}{ }^{19}$ & 2012 & 72 & $5.6 \%$ & $85.3 \%$ \\
\hline
\end{tabular}

quantitative variables like gender, obesity, smoking, hyperlipidemia, co-morbid illnesses, limb involved, procedure performed and outcomes in terms of graft patency, wound infection, limb salvage and mortality. Chi-square test was applied after data stratification in terms of age, gender, smoking and co-morbid illnesses taking $p$-value of $\leq 0.05$ as statistically significant.

\section{RESULTS}

A total of 23 patients were included in the study. The mean age of patients was $71.04 \pm 7.29$ years with a range of $50-80$ years. Twenty one
The summary of distribution of patients according to age, gender, presentation, smoking, obesity, hyperlipidemias and co-morbid conditions is given in table-I.

All the patients had their Aortofemoral bypass surgeries under GA with additional femoropopliteal bypass performed in 1 patient $(4.3 \%)$ having concomitant occlusion of SFA during the same setting using ipsilateral great saphenous vein graft in reverse fashion. The disease was more profound in the right lower limb in 15 patients $(65.2 \%)$. 
Regarding the outcomes, two patients (8.7\%) developed superficial SSI who were managed by intravenous antibiotics. In our study, one patient (4.3\%) who was an 80 years old male with DM, HTN and IHD died despite having undergone below knee amputation. The limb survival rate was $91.3 \%$ after two years. The outcomes of the study are shown in table-II below.

\section{DISCUSSION}

The management of aortoiliac occlusive disease is a rapidly evolving field in vascular medicine and surgery. There are multiple approaches that must be considered, ranging from medical management to endovascular and open surgical procedures ${ }^{9,10}$. Aortofemoral bypass is the most common open surgical method used to treat aortoiliac occlusive disease. In the early experience of aortic surgery, unilateral $\mathrm{ABF}$ or even Aortoiliac bypass was performed to limit the extent of the procedure. However, as more experience was gained with these operations, using the common femoral arteries as the outflow target clearly produced better long-term patency results ${ }^{11}$.

The mean age of patients in our study was $71.04 \pm 7.29$ years. Ashraf et al in 2015 reported a mean age of $58.32 \pm 6.60$ years in patients presenting with aortoiliac occlusive disease ${ }^{12}$. A study by Sen et al from India reported a younger mean age of 53 years ${ }^{11}$. Our study comprised of $91.3 \%$ male patients. Ashraf et al and Sen et al reported the frequency of male patients to be $76 \%$ and $91 \%$ respectively ${ }^{11,12}$. On the contrary, Sharma et al reported a higher number of female patients with a frequency of $56.4 \% 13$. Graft survival was also found to be significantly associated with gender in our study $(p=0.030)$.

The graft survival rate after 2 years in our study was $91.3 \%$. Similarly Sen et al reported graft survival rate of $84 \%$ on 2 years follow-up. Our mortality rate of $4.3 \%$ is also comparable to the mortality rate of $3 \%$ reported by Sen et al11. Danczyk et al reported a higher mortality rate of $11.6 \%$ in patients undergoing aortofemoral bypass surgery at 2 years follow-up ${ }^{13}$.
A study by Dorigoet al in 2017 compared the outcomes of aortofemoral bypass and kissing stentsin patients presenting with aortoiliac occlusive disease ${ }^{14}$. A total of 82 patients underwent aortofemoral bypass surgery. There were 2 cases of peri operative graft thrombosis. None of the patients required amputation. Cumulative local and systemic complications were recorded in 17 patients. There was 1 peri operative death. Mean duration of follow up in that study was 38 months. The overall graft patency rateat 6 year was $65.5 \%$. In our study, we had one major amputation and three fore foot amputations. Graft thrombosis was seen in 1 case. However our results are based on a two year follow-up only.

The limitations of our study was the small sample size and the duration of follow up being two years. We are however following the patients and will report on their long term follow up in due course of time. But the study is still the first of its kind on the topic in Pakistan. Few of the studies showing their outcomes for aortofemoral bypass surgery published in literature are shown in table-IV. The patients operated after 2000 in study by Sharma et al have been quoted.

\section{CONCLUSION}

Aortofemoral bypass surgery is a safe and highly effective treatment modality for the management of aortoiliac occlusive arterial disease in experienced hands. Limb salvage can be successfully achieved in more than $91.3 \%$ cases. Although the duration of follow up in our study was relatively short but results are in line with many other contemporary studies in literature.

\section{CONFLICT OF INTEREST}

This study has no conflict of interest to be declared by any author.

\section{REFERENCES}

1. Clair DG, Beach JM. Strategies for managing aortoiliac occlusions: access, treatment and outcomes. Expert Rev Cardiovasc Ther 2015; 13(5): 551-63.

2. Kasapis C, Gurm HS. Current approach to the diagnosis and treatment of femoral-popliteal arterial disease. A systematic review. Curr Cardiol Rev 2009; 5(4): 296-311.

3. Pandey A, Banerjee S, Ngo C, Mody P, Marso SP, Brilakis ES, et al. Comparative efficacy of endovascular revascularization versus supervised exercise training in patients with intermittent 
claudication: meta-analysis of randomized controlled trials. JACC Cardiovasc Interv 2017; 10(7): 712-4.

4. Kim JH, So BJ, Byun SJ, Kim KY. The advantage of common femoral endarterectomy alone or combined with endovascular treatment. Vasc Specialist Int 2018; 34(3): 65-71.

5. Wylie EJ. Experimental and clinical experiences with the use of fascia lata applied as a graft about major arteries after thromboendarteriectomy and aneurysmorrhaphy. Surg Gynecol Obstet 1951; 93(3): 257-72.

6. Jaff MR, White CJ, Hiatt WR, Fowkes GR, Dormandy J, Razavi $\mathrm{M}$, et al. An update on methods for revascularization and expansion of the TASC lesion classification to include below-the-knee arteries: a supplement to the inter-society consensus for the management of peripheral arterial disease (TASC II): The TASC Steering Committee. Ann Vasc Dis. 2015; 8(4): 343-57.

7. Lau H. Long-term outcome of aortofemoral bypass for aortoiliac occlusive disease. Ann Acad Med Singapore 2000; 29(4): 434-8.

8. Novo S, Coppola G, Milio G. Critical limb ischemia: definition and natural history. Curr Drug Targets Cardiovasc Haematol Disord 2004; 4(3): 219-25.

9. Morisaki K, Yamaoka T, Iwasa K, Ohmine T. Outcomes of endovascular therapy for infrarenal aortic occlusion of TASC II D classification. Ann Vasc Surg 2017; 43(1): 203-9.

10. Apigian AK, Landry GJ. Basic data underlying decision making in nonatherosclerotic causes of intermittent claudication. Ann Vasc Surg 2015; 29(1): 138-53.

11. Sen I, Stephen E, Agarwal S.Clinical profile of aortoiliac occlusive disease and outcomes of aortobifemoral bypass in India. J Vasc Surg 2013; 57(Suppl-2): 20-25.
12. Ashraf T, Yousuf K, Karim MT. Early experience of endovascular treatment of peripheral vascular disease. J Ayub Med Coll Abbottabad 2015; 27(1): 93-95.

13. Danczyk RC, Mitchell EL, Petersen BD, Edwards J, Liem TK, Landry GJ, et al. Outcomes of open operation for aortoiliac occlusive disease after failed endovascular therapy. Arch Surg 2012; 147(9): 841-45.

14. Dorigo W, Piffaretti G, Benedetto F, Tarallo A, Castelli P, Spinelli $\mathrm{F}$, et al. Comparison between aortobifemoral bypass and aortoiliac kissing stents in patients with complex aortoiliac obstructive disease. J Vasc Surg 2017; 65(1): 99-107.

15. Sharma G, Scully RE, Shah SK, Madenci AL, Arnaoutakis DJ, Menard MT, et al. Thirty-year trends in aortofemoral bypass for aortoiliac occlusive disease. J Vasc Surg 2018; 68(6): 1796-1804.

16. Tanaka A, Sandhu HK, Perlick A, Miller CC, Saqib NU, Safi HJ, et al. Superficial femoral artery occlusion reduces aortofemoral bypass graft patency. Eur J Vasc Endovasc Surg 2019; 57(5): 650-57.

17. Chiu KW, Davies RS, Nightingale PG, Bradbury AW, Adam DJ. Review of direct anatomical open surgical management of atherosclerotic aorto-iliac occlusive disease. Eur J Vasc Endovasc Surg 2010; 39(4): 460-71.

18. Igari K, Kudo T, Katsui S, Nishizawa M, Uetake H. The comparison of long-term results between aortofemoral and axillofemoral bypass for patients with aortoiliac occlusive disease. Ann Thorac Cardiovasc Surg 2020; 10(1): 00300.

19. Lee GC, Yang SS, Park KM, Park Y, Kim YW, Park KB, et al. Ten year outcomes after bypass surgery in aortoiliac occlusive disease. J Korean Surg Soc 2012; 82(6): 365-69. 